\title{
Hemotropic Mycoplasmosis - Emerging Cause of Infectious Anaemia in Dogs and Cats
}

\author{
P. Ameldev* and P.V. Tresamol \\ College of Veterinary and Animal Sciences, Mannuthy, Kerala Veterinary and Animal \\ Sciences University, Kerala, India \\ *Corresponding author
}

\section{A B S T R A C T}

\section{Keywords}

Infectious anaemia, Haemobartonella,

Feline, Haemotropic mycoplasma

\section{Article Info}

Accepted:

12 December 2017

Available Online:

10 January 2018
Mycoplasmas are one of the smallest bacteria and are divided into two groups, haemotropic and non-haemotropic mycoplasmas. Hemotrophic mycoplasmas (hemoplasmas) are uncultivable cell wall-less bacteria, previously known as Haemobartonella and Eperythrozoon species. They are gram-negative, obligate red cell parasites and it is considered as pleomorphic. They can be seen as rod, spherical, or ring-shaped organisms and are found individually or in chains across the red cell surface. Hemoplasmas can cause acute hemolytic anemia in dogs and cats. The clinical spectrum of infection ranges from asymptomatic to life threatening, depending partially on host susceptibility. There are also reports in rats (H. muris), raccoons (H. procyoni), an opossum, monkeys and human beings.

\section{Etiology}

The feline haemoplasma species that are currently recognised vary in pathogenicity, with some isolates consistently inducing haemolytic anaemia whereas others result in few noticeable clinical signs. In feline four major species cause the infection and they are Mycoplasma haemofelis, Candidatus Mycoplasma haemominutum, Candidatus Mycoplasma turicensis and Candidatus Mycoplasma haematoparvum-like (Tasker et al., 2003).

Mycoplasma haemocanis and candidatus Mycoplasma hematoparvam are the two species of mycoplasmas in dogs which have affinity towards erythrocytes. This was previously classified as a Haemobartonella species, has recently been positioned within the genus Mycoplasma by 16S rRNA analysis (Messick, 2004).

\section{Epidemiology}

Adult cats are more prone to the infection than the young ones, once the animal is infected it is difficult to eliminate the organism even after prolong antibiotic therapies. The animal may act as an asymptomatic carrier. It is reported that male cats are more likely to get the infection due to 
the fighting behavior, fighting injuries is considered as the one of the major source of transmission.

Clinical cases of hemoplasmosis in dogs have occasionally been reported, but co-factors such as splenectomy, immunosuppression, or concurrent infections seem to play a role in the pathogenesis.

\section{Transmission}

The cat flea Ctenocephalides felis has been incriminated in the transmission of haemoplasmosis between cats (Woods et al., 2005). The dog tick Rhipicephalus sanguineus, a proposed vector for canine hemoplasmas (Roura et al., 2010). Transstadial and transovarial transmission in ticks has also been described, indicating that the tick may be an important reservoir as well as a vector of infection.

Blood transfusions have been reported to cause infection (Willi et al., 2007). The use of freshly collected blood from a hemoplasma-infected blood donor for transfusion would very likely result in transmission of infection to the recipient cat.

Other possible modes of hemoplasma transmission include vertical transmission from queen to kittens during pregnancy, at birth or via lactation.

Although not reported, transmission may also be possible via the use of multiuse vials or the inappropriate use of the same equipment (e.g., surgical instruments) on different animals without adequate cleaning/sterilization, particularly if blood contamination was significant and only a short time elapsed between consecutive procedures (Tasker, 2010).

\section{Pathogenesis}

Hemolytic anaemia is the most significant pathogenic effect in case of this disease; most of the haemolysis associated with haemoplasma infection is believed to be extravascular in nature, occurring in the spleen and liver especially, but also in the lungs and bone marrow. Intravascular haemolysis has also been reported, as has increased osmotic fragility of haemoplasma infected red blood cells. Positive Coombs' tests and autoagglutination, indicating the presence of erythrocyte-bound antibodies. Such erythrocyte-bound antibodies could be responsible for immune-mediated destruction of red blood cells.

The severity of disease produced by $M$. haemofelis varies, with some cats having mild anemia and no clinical signs and others having marked depression and severe anemia leading to death. Some damage to erythrocytes may be caused directly by the organism, but immune mediated injury appears to be more important. The attachment of organisms to erythrocytes either exposes hidden erythrocyte antigens or results in altered erythrocyte antigens, with a subsequent host response of producing antierythrocyte antibodies. However, another possible mechanism of immune-mediated injury should also be considered. If antibody-mediated complement fixation occurs, the erythrocytic membrane may be damaged as an "innocent bystander". The anaemia occurs primarily as a result of extravascular erythrophagocytosis by macrophages in the spleen, liver, lungs, and bone marrow (Messick, 2004).

\section{Clinical signs}

The disease has been divided into four phases, pre-parasitemic, acute, recovery, and carrier phases. The pre-parasitemic phase is generally about 1 to 3 weeks after intravenous injection. The acute phase of disease represents the time from the first to the last major parasitemia. Organisms generally appear in the blood in a cyclic manner within discrete parasitemic episodes. The number of organisms generally increases to a peak value over one to five days, followed by a rapid decline. Repetitive parasitemic episodes appear to cause progressive erythrocyte damage and shortened erythrocyte life spans. 
Clinical signs of haemoplasma infection depend on factors such as the species involved, stage of infection and presence of concurrent infections. Common signs exhibited are pallor, lethargy, anorexia, weight loss, depression and dehydration. Intermittent pyrexia is often seen, particularly in the acute stages of disease, as is splenomegaly, which may reflect extramedullary haematopoiesis. Jaundice is uncommon unless severe acute haemolysis occurs.

\section{Diagnosis}

Microscopic examination of the blood smears is the most common way to detect mycoplasmas. Blood smear are dyed with Romanowsky stains including Giemsa, Wright and Wright-Giemsa. Microscopic observation demonstrates bacteria in single, pairs or chain on the surface of erythrocytes. The chance of getting false negative results are more in this case, dye sediment caused by inappropriate staining or fixation may be confused with the bacteria. Along with this, Howell-Jolly bodies may also be confused with the bacteria. So the specificity of blood smear examination is poor, but it can be used as a tool for primary screening. Additionally cytology cannot differentiate between haemoplasma species. When anaemia is induced by haemoplasma infection, it is typically regenerative macrocytic, and normo or hypochromic. Release of sequestered erythrocytes from the spleen may also result in a marked rise in red blood cell count without an accompanying reticulocytosis. Positive Coombs' tests and auto-agglutination may also occur. Serum biochemistry may reveal hyperproteinaemia due to dehydration or an acute phase response, and increased liver enzyme levels may arise from hepatic hypoxic damage. Hyperbilirubinaemia can result from the hemolysis (Tusker, 2010).

Polymerase chain reaction amplifies specific lengths of DNA so that potentially tiny amounts of DNA in samples are detectable. Polymerase chain reaction is known to be more sensitive than cytology for haemoplasma detection. It has got the potential to differentiate the species of mycoplasmas and assays are based on amplification of segments of the haemoplasma 16S rRNA gene (Ghazisaeedi et al., 2014).

\section{Treatment}

Haemotropic Mycoplasmas are sensitive to tetracyclines which specifically inhibit protein synthesis in Prokaryotes. The preferred tetracycline derivative used is doxycycline due to fewer side effects and less frequent dosing. The recommended doxycycline dose is 5-10 $\mathrm{mg} / \mathrm{kg}$ P.O once daily (mixed with honey or oil). Therapy should be continued for 14 to 21 days depending on response to treatment, although the tetracyclines are effective for the treatment of anemia, treatment does not eliminate the causal organism.

Enrofloxacin has also been recommended for the treatment of haemobartonellosis at a dose of $10 \mathrm{mg} / \mathrm{kg}$ P.O daily for at least 14 days (Winter et al., 1993). The macrolide azithromycin, which is effective for the treatment of several Mycoplasma associated syndromes in humans, was recently found to be ineffective in the treatment of haemobartonellosis (Westfall et al., 2001).

The anemia induced by $H$. felis is thought to be immune-mediated so glucocorticoids may be indicated. It is important that concurrent diseases such as toxoplasmosis, which could be exacerbated by the use of glucocorticoids, are ruled out first. The recommended dose of prednisolone is $2 \mathrm{mg} / \mathrm{kg}$ per day P.O, alongside antibiotic therapy, with a tapering of dosage over 3 weeks (Hoskins and Barta, 1984).

Supportive care including whole blood transfusion may be required in severely anemic cats. If the anemia is severe (haematocrit less than $12 \%$ ) or if the PCV has dropped rapidly, a blood transfusion may be necessary. Feline blood transfusions should only be performed with typed or cross-matched recipient and donor blood to avoid potentially fatal blood transfusion reactions (Tusker and Lupin, 2002). 


\section{Prevention and control}

Control of ectoparasites should be the primary aim, regular grooming and use of ectoparasiticidals are also recommended. Reduce outdoor asses to cats which may leads to fighting injuries. Blood donors should be screened using PCR-based DNA assays to prevent transmission to transfusion recipients. Iatrogenic transmission can be avoided by using properly sterilized needles and equipment. Control of arthropod vectors is recommended, as is minimizing stress in herd and flock situations.

\section{References}

Ghazisaeedi, F., Atyabi, N., Salehi, T.Z., Gentilini, F., Tamai, I.A., Akbarein, H. and Tasker, S. 2014. A molecular study of hemotropic mycoplasmas (hemoplasmas) in cats in Iran. Vet. Clin. Pathol. 43: 381386.

Hoskins, J.D. and Barta, O., 1984. Concurrent Haemobartonella felis and Toxoplasma gondii infections in a cat. Vet. Med. Small Anim. Clinician.

Messick, J.B., 2004. Hemotrophic mycoplasmas (hemoplasmas): a review and new insights into pathogenic potential. Vet. Clin. Pathol. 33(1):2-13.

Roura, X., Peters, I.R., Altet, L., Tabar, M.D., Barker, E.N., Planellas, M., Helps, C.R., Francino, O., Shaw, S.E. and Tasker, S. 2010. Prevalence of hemotropic mycoplasmas in healthy and unhealthy cats and dogs in Spain. J. Vet. Diagn. Invest. 22: 270-274.

Tasker, S. and Lappin, M.R., 2002.
Haemobartonella felis: recent developments in diagnosis and treatment. J. Feline Med. Surgery. 4(1): 3-11.

Tasker, S., 2010. Haemotropic mycoplasmas: what's their real significance in cats? $J$. feline med. Surg. 12(5): 369-381.

Tasker, S., Binns, S.H., Day, M.J., GruffyddJones, T.J., Harbour, D.A., Helps, C.R., Jensen, W.A., Olver, C.S. and Lappin, M.R., 2003. Use of a PCR assay to assess the prevalence and risk factors for Mycoplasma haemofelis and Candidatus Mycoplasma haemominutum in cats in the United Kingdom. Vet. Record. 152(7): 193-198.

Westfall, D.S., Jensen, W.A., Reagan, W.J., Radecki, S.V. and Lappin, M.R., 2001. Inoculation of two genotypes of Hemobartonella felis (California and Ohio variants) to induce infection in cats and the response to treatment with azithromycin. Am. J. Vet. Res. 62(5):687691.

Willi, B., Boretti, F.S., Tasker, S., Meli, M.L., Wengi, N., Reusch, C.E., Lutz, H. and Hofmann-Lehmann, R., 2007. From Haemobartonella to hemoplasma: molecular methods provide new insights. Vet. Microbiol, 125(3): 197-209.

Winter, R.B., 1993. Using quinolones to treat hemobartonellosis. Vet. Med. 88(4): 306.

Woods, J. E., Brewer, M. M., Hawley, J. R., Wisnewski, N., and Lappin, M. R. 2005. Evaluation of experimental transmission of Candidatus Mycoplasma haemominutum and Mycoplasma haemofelis by Ctenocephalides felis to cats. Am. J. Vet. Res. 66(6): 1008-1012.

\section{How to cite this article:}

Ameldev, P. and Tresamol, P.V. 2018. Hemotropic Mycoplasmosis - Emerging Cause of Infectious Anaemia in Dogs and Cats. Int.J.Curr.Microbiol.App.Sci. 7(01): 1308-1311. doi: https://doi.org/10.20546/ijcmas.2018.701.159 